\title{
Haemorrhagic colitis: detection of verotoxin producing Escherichia coli 0157 in a clinical microbiology laboratory
}

\author{
C W WALKER, REBECCA UPSON, R E WARREN \\ From the Clinical Microbiology and Public Health Laboratory, Addenbrooke's Hospital, Cambridge
}

SUMMARY Faeces $(n=1319)$ were examined over three months for the presence of non-sorbitol $\stackrel{\overrightarrow{.}}{-}$ fermenting, verotoxin producing Escherichia coli (serotype 0157). Seven isolates were found, four ${ }_{0}^{\circ}$ from patients with bloodstained diarrhoea and three from patients with no evidence of blood in the 을 faeces. Screening of all faecal samples with specific 0157 antiserum for non-sorbitol fermenting $\rightarrow$ organisms and agglutination was an important adjunct to clinical and microscopic findings and $c$ helped detect cases of verotoxin producing $E$ coli which might otherwise have been missed.

Strains of Escherichia coli cytotoxic to Vero cells were first described in 1977 by Konowalchuk et al, ${ }^{\prime}$ who showed that some strains of serotypes 026,0111 , and 0128 produced a toxin that was active against Vero cells (African Green monkey) in tissue culture. The cytopathic effect was distinct from that produced by the heat labile toxin. The occurrence of verotoxin producing strains of $E$ coli has now been widely reported..$^{2-4} \mathrm{O}^{\prime}$ Brien et al reported that verotoxin is closely related to the Shiga toxin produced by strains of Shigella dysenteriae type $1 .{ }^{5}$ Scotland et al discovered two distinct verotoxins (VT1 and VT2) when performing neutralisation tests with antiserum to Shiga toxin. ${ }^{6}$

Two clinical conditions are associated with verotoxin producing $E$ coli; haemolytic uraemic syndrome and haemorrhagic colitis. Haemolytic uraemic syndrome, a severe illness of young children, is characterised by microangiopathic haemolytic anaemia, thrombocytopenia, and renal failure. It is associated with the presence of verotoxin producing $E$ coli in the gastrointestinal tract. Various serotypes have been implicated including $026,0111,0113,0121$, 0145 and particularly $0157 .^{7-9} \mathrm{~A}$ recent report linked two cases of haemolytic uraemic syndrome with the consumption of unpasteurised milk, and case to case transmission has also been described. ${ }^{1011}$

Haemorrhagic colitis, which usually occurs in adults, is characterised by the acute onset of severe abdominal pain and profuse diarrhoea, usually

Accepted for publication 8 July 1987 bloody, and has so far been associated with one $\vec{\varphi}$ particular serotype of $E$ coli- $-0157: \mathrm{H} 7 .^{47}$ Outbreaks, $\stackrel{\infty}{\infty}$ as well as sporadic cases, have been reported in the United States and Canada and have been linked to undercooked hamburgers and unpasteurised milk. ${ }^{12-16}$

During investigation of American outbreak strains, verotoxin producing $E$ coli (serotype 0157 ) were found $\stackrel{\circ}{\Phi}$ to be unusual in their inability to ferment sorbitol ${ }^{17}$ and their possession of $\mathrm{H} 7$ antigen. ${ }^{18}$ March and Ratnam evaluated sorbitol-MacConkey medium for the $E$ coli $0157: \mathrm{H} 7$ in Newfoundland, Canada. ${ }^{19}$ They found that only $15 \%$ of faecal enterobacteria were non-sorbitol fermenters (NSF) and suggested that this medium could be used to screen clinical specimens. $\frac{0}{-}$ Haldane et al reported that all of their isolates of $E$ coli 3 . 0157:H7 produced lysine and ornithine decarboxylase 8 and that this characteristic could also be used to screen for $E$ coli $0157: \mathrm{H}^{20} .^{20}$

In East Anglia, during the summer months of 1985, two laboratories noted an unusual increase in the number of bloodstained faeces from patients with diarrhoea, $E$ coli 0157 the causative agent, being o recovered from 24 patients. No common link was $N$ found between the cases, although a case control study ్ㅔ suggested that the way in which vegetables had been 0 prepared was to blame. ${ }^{21}$ In the summer of 1986, therefore, we decided to investigate the incidence of verotoxin producing $E$ coli 0157 in Cambridge. The $\stackrel{\$}{\rightarrow}$ following report describes the development of a technique for the detection of verotoxin producing $E \vec{O}$ coli 0157 in a clinical laboratory and our subsequent findings. 


\section{Material and methods}

All faeces received by the Clinical Microbiology and Public Health Laboratory, Cambridge, between 11 June and 16 September 1986 were included in the trial. They were inoculated on to MacConkey agar, which contained $1 \%$ sorbitol in place of lactose (Oxoid Ltd, $\mathrm{CM} 813$ ). After overnight incubation at $37^{\circ} \mathrm{C} \mathrm{NSF}$ colonies were identified by multipoint inoculation. Isolates were tested for oxidase; Voges-Proskauer reaction; adonitol, inositol, lactose, raffinose and rhamnose fermentation; hydrogen sulphide, indole and urease production; citrate utilisation; tryptophan deamination and anaerobic fermentation of glucose. Lysine, ornithine, and arginine decarboxylation were performed using a modified version of the method of Falkow, ${ }^{22}$ using bromothymol blue in place of bromocresol purple, and incubation in an anaerobic atmosphere instead of oil overlay. A sorbitol fermentation test was also included to act as confirmation of the primary fermentation result from the sorbitolMacConkey medium. All organisms were inoculated on to cystine lactose electrolyte deficient agar as a check for purity. After incubation results were entered into a microcomputer to identify the organism using a profile index developed in the laboratory.

Those isolates identified as $E$ coli were tested for agglutination with experimental 0157 antiserum (Wellcome Diagnostics) using slide and tube agglutination techniques. For the slide test, colonies from purity plates were emulsified in phosphate buffered

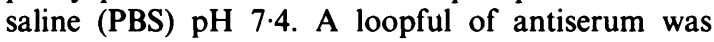
applied and mixed and the slide was rocked and examined for agglutination. The tube test was performed in microtitre trays. Isolates were inoculated into brain heart infusion broth (Difco Laboratories, 003717) and incubated for 18 hours at $37^{\circ} \mathrm{C}$. Cultures were then boiled for 30 minutes and diluted $1 / 100$ to give an organism suspension of about $10^{7} \mathrm{cfu} / \mathrm{ml}$. Twofold dilutions of 0157 antiserum were made in PBS, from $1 / 4$ to $1 / 256$, to give a volume of $100 \mu \mathrm{l}$ in each well. The organism suspension was added to give a final volume of $200 \mu \mathrm{l}$ and a final range of antiserum dilutions from $1 / 8$ to $1 / 512$. The tray was incubated for four hours at $37^{\circ} \mathrm{C}$, followed by $4^{\circ} \mathrm{C}$ overnight, and examined for a carpet of agglutination. A known $E$ coli serotype 0157 (kindly supplied by the Enteric Pathogens Reference Laboratory, Central Public Health Laboratory, Colindale, London) was included in each batch. Isolates identified as $E$ coli 0157 were confirmed as $E$ coli using the API 20 E strip (API Products Ltd).

All NSF $E$ coli isolates were stored at $-70^{\circ} \mathrm{C}$. Verotoxin production was tested by a modification of the method of Karmalia et al. ${ }^{23}$ The isolates were inoculated into brain heart infusion broth and incubated for 18 hours at $37^{\circ} \mathrm{C}$. The growth was harvested by centrifugation and washed twice with PBS. The supernatant fluid was discarded and the organisms were treated with polymixin B $0.1 \mathrm{mg} / \mathrm{ml}$ (Sigma Chemicals Ltd) for 30 minutes at $37^{\circ} \mathrm{C}$. After centrifugation the supernatant fluid was inoculated on to a monolayer of Vero cells (prepared in microtitre trays) and incubated for three days at $37^{\circ} \mathrm{C}$. The cells were examined daily for cytopathic effects. A known verotoxin producing $E$ coli (kindly supplied as above) was included in each batch.

During the trial, those faeces from which E coli 0157 had been isolated were stored at $-20^{\circ} \mathrm{C}$. These faeces were examined as a batch for the presence of verotoxin. Thawed faeces were suspended in an equal volume of PBS and centrifuged at $14000 \mathrm{~g}$ for two minutes (Eppendorf Microfuge). The supernatant fluid was sterilised by filtration $(0.22 \mu \mathrm{m}$, Millipore) and inoculated on to a monolayer of Vero cells. The cells were incubated for three days at $37^{\circ} \mathrm{C}$ and examined daily for cytopathic effects.

Clinical details supplied by practitioners were retrospectively subjected to text analysis using the Microseek database search facility on the laboratory's minicomputer (ITL-PHLS Microlab). This listed those patients with bloodstained diarrhoea. Using the same facility, laboratory results were analysed for those samples where microscopy had shown the presence of red blood cells.

\section{Results}

During the trial, 1319 faecal samples were examined. Two hundred and eleven NSF organisms were isolated, giving a faecal carriage rate of $16 \%$. Of these, $86(41 \%)$ were $E$ coli. On further examination 21 of 86 (24\%) E coli proved to be sorbitol fermenters. Table 1 lists the remaining NSF organisms.

Sixty five NSF $E$ coli isolates were tested for agglutination with the 0157 antiserum, for verotoxin production, and for lysine and ornithine decarboxylation. Six strains agglutinated in both the slide and tube tests. These six strains produced a cytopathic effect on Vero cells after 24 hours' incubation. One of the remaining isolates also produced verotoxin; this isolate was retested and found to agglutinate with the 0157 antiserum. These seven isolates were subsequently confirmed as verotoxin producing $E$ coli 0157 by the Enteric Pathogens Reference Laboratory, Colindale, London. Of the seven strains of verotoxin producing $E$ coli 0157 , six produced both lysine and ornithine decarboxylase. One failed to produce either (table 2).

Of the seven faecal samples which yielded $E$ coli 0157 , two samples produced a cytopathic effect that was detected only after three days' incubation. No 
Table 1 Identification of non-sorbitol fermenters

\begin{tabular}{lc}
\hline Organism & $\begin{array}{l}\text { No of } \\
\text { isolates }(\%)\end{array}$ \\
\hline Escherichia coli & $87(40 \cdot 7)$ \\
Proteus sp & $64(30 \cdot 3)$ \\
Pseudomonas aeruginosa & $18(8 \cdot 5)$ \\
Enterobacter sp & $17(8 \cdot 1)$ \\
Hafnia alvei & $6(2 \cdot 8)$ \\
Klebsiella sp & $6(2 \cdot 8)$ \\
Providencia sp & $5(2 \cdot 4)$ \\
Aeromonas sp & $3(1 \cdot 4)$ \\
Citrobacter sp & $3(1 \cdot 4)$ \\
Serratia sp & $2(0 \cdot 9)$ \\
Salmonella sp & $1(0 \cdot 5)$ \\
Total & $211(100)$ \\
\hline
\end{tabular}

Table 2 Production of lysine and ornithine decarboxylase of NSF E coli

\begin{tabular}{|c|c|c|c|c|}
\hline $\begin{array}{l}\text { lys }+ \\
\text { orn }+\end{array}$ & $\begin{array}{l}\text { lys + } \\
\text { orn - }\end{array}$ & $\begin{array}{l}\text { lys - } \\
\text { orn + }\end{array}$ & $\begin{array}{l}\text { lys - } \\
\text { orn - }\end{array}$ & Total \\
\hline $\begin{array}{l}E \text { coli } 0157 \\
\text { verotoxin + } \\
\text { Other NSF E coli } 24\end{array}$ & $\begin{array}{r}0 \\
17\end{array}$ & $\begin{array}{r}0 \\
12\end{array}$ & $\begin{array}{l}1 \\
5\end{array}$ & $\begin{array}{r}7 \\
58\end{array}$ \\
\hline
\end{tabular}

cytopathic effect was detected in the remaining five samples.

During the trial, 80 faecal samples from patients with a history of bloodstained diarrhoea or microscopic evidence of red blood cells were recorded. Of these, four yielded $E$ coli 0157 and 22 yielded other faecal pathogens: Campylobacter sp $(\mathrm{n}=15)$, Salmonella sp $(\mathrm{n}=6)$, and Shigella sonnei $(\mathrm{n}=1)$. The remaining three isolates of $E$ coli 0157 were from patients with no clinical details of bloodstained diarrhoea and who had no red blood cells on microscopy.

\section{Discussion}

Sorbitol-MacConkey medium was a useful medium for the isolation of NSF $E$ coli. Non-sorbitol fermenting organisms were easily distinguished and were similar in appearance to non-lactose fermenting organisms on conventional MacConkey agar. The isolation rate of NSF organisms was $15.9 \%$, which is similar to the findings of March and Ratnam, ${ }^{19}$ but substantially lower than the 28 of 51 isolated from referred samples reported by Smith et al. ${ }^{24}$ The commonest NSF organisms, other than $E$ coli, were Proteus sp and Pseudomonas aeruginosa. These could easily be excluded by performing rapid biochemical tests - urease and oxidase-on the colonies. This would reduce the necessity for full identification of all
NSFs and would be of particular benefit to those laboratories relying on commercial kits for their identification. We considered that confirmation of 은 sorbitol fermentation was important. Our sorbitol $\overrightarrow{\bar{B}}$ check excluded 21 of $86 \mathrm{E}$ coli isolates from further work. The presence of late sorbitol fermenters and misinterpretation of apparent sorbitol fermentation in areas of high inoculum may have contributed to this initial overestimate.

The association of non-sorbitol fermentation with कै strains of $E$ coli in haemorrhagic colitis was first $\vec{\circ}$ described by Wells et al during their investigation of strains from outbreaks in Oregon and Michigan, $\vec{\omega}$ USA. ${ }^{17}$ This was subsequently confirmed by March and Ratnam in Newfoundland, Canada. ${ }^{19}$ Our finding that 7 of 65 NSF strains were verotoxin producing $E \doteq$ coli 0157 supports the findings of Smith et al that British strains are similar. ${ }^{24}$ There has, however, been $\%$ one published report of a sorbitol fermenting isolate of 을 verotoxin producing $E$ coli 0157 from a patient with haemorrhagic colitis. ${ }^{18}$ We have also seen a similar $\vec{c}$ strain, isolated outside the period of the trial. This was from a patient with bloodstained diarrhoea in whom $E$ g coli 0157 was suspected (unpublished data). These results suggest that non-sorbitol fermentation is $\overrightarrow{0}$ not an invariable marker. The occurrence of $\stackrel{\infty}{\infty}$ verotoxin production in serotypes other than 0157 in haemorrhagic colitis and haemolytic uraemic syndrome suggests that there is no obvious reason why the absence of sorbitol fermentation should be linked genetically to verotoxin production. Direct detection of verotoxin producing $E$ coli by the use of DNA probes is being developed. It is more sensitive, but is not generally available in diagnostic laboratories. Until then, our study has shown that sorbitol-MacConkey agar coupled with agglutination is helpful.

Haldane et al recommended the inclusion of lysine and ornithine decarboxylation with sorbitol non-fermentation as an improved biochemical screen. ${ }^{20}$ They found that all of their 37 verotoxin producing $E$ coli 0157 produced both lysine and ornithine decarboxylase. In our study six of seven strains produced lysine and ornithine decarboxylase, but one strain was negative for both. Isolates of verotoxin producing $E$ coli have also been reported to be characteristically of raffinose fermenters and $\beta$-glucuronidase non- $\tilde{O}$ producers. ${ }^{25}{ }^{26}$ We believe that these additional biochemical variables are of less use than confirmation of serotype and verotoxin production, both of which are available to laboratories with access to cell culture.

Slide and tube agglutination techniques seem to be $\stackrel{\mathscr{D}}{?}$ equally reliable. Slide agglutination was quick and easy to perform while tube agglutination was more time consuming and a result took a day longer. Isolates of $E$ coli can be screened by slide agglutination 
from the sorbitol-MacConkey medium, with positive or equivocal results being confirmed by tube agglutination.

All of our isolates of $E$ coli 0157 produced verotoxin. The cytopathic effect of verotoxin was easy to distinguish and differed clearly from that of the heat labile toxin of $E$ coli and the cytotoxin of Clostridium difficile. The cytopathic effect was observed after 24 hours' incubation so that it may not be necessary to incubate for three days. Our laboratory method for detection of verotoxin production was specific, with all positive results being confirmed by the reference laboratory.

Karmali et al detected verotoxin in all of five faecal samples that yielded verotoxin producing $E$ coli and in two samples from which no verotoxin producing $E$ coli were isolated. ${ }^{7}$ Similarly, Krishnan et al found verotoxin in 17 of 18 cases in which $E$ coli 0157 were isolated and in an additional seven samples from which no verotoxin producing $E$ coli were isolated.$^{25} \mathrm{In}$ our study, however, only two of seven samples which yielded verotoxin producing $E$ coli 0157 showed faecal verotoxin. This may have been due to an insensitive technique or to storage of unbuffered faeces. Detection of verotoxin in faeces seems to be of limited use until this technique is further validated and specific neutralising antitoxin becomes available.

Four of the $E$ coli 0157 isolates were from the 80 patients who presented with bloodstained diarrhoea. No evidence of bloodstained diarrhoea was found in the remaining three patients: failure by clinicians to record that diarrhoea was bloodstained, low,numbers of organisms present, or samples being submitted more than one week after onset of the illness may have contributed to this..$^{13141725}$ Thus these three cases would have been missed if the decision to culture for $E$ coli 0157 had rested on clinical and microscopic findings alone. Until the epidemiology of and familiarity with this condition increases, it seems unwise to restrict examination of faeces for this pathogen on the basis of clinical history or microscopy.

It is important that clinical microbiology laboratories are able to isolate and identify this new pathogen because of the implications for diagnosis of haemorrhagic colitis and clinical management, including surgery. DNA probes have been developed for the detection of verotoxin but are not available to most clinical laboratories. The more sensitive technique of application of DNA probes to cultures resulted in a greater detection of verotoxin producing $E$ coli in the trial of Smith et al. ${ }^{24}$ Screening for NSF organisms followed by slide agglutination seems to be a simple, inexpensive and sensitive alternative. It can easily be incorporated into routine methods on all faecal samples, particularly as commercial supplies of media and antisera are now available. Detection of verotoxin production may then be performed for confirmation if Vero cell cultures are available.

We thank Oxoid Ltd for the supply of sorbitolMacConkey medium and Wellcome Diagnostics for the 0157 antiserum.

\section{References}

1 Konowalchuk J, Speirs JI, Stavric S. Vero response to a cytotoxin of Escherichia coli. Infect Immun 1977;18:775-9.

2 Wade WG, Thom BT, Evans N. Cytotoxic enteropathogenic Escherichia coli. Lancet 1979;ii:1235-6.

3 Wilson MW, Bettelheim KA. Cytotoxic Escherichia coli serotypes. Lancet 1980;i:201.

4 Centres for Disease Control. Isolation of $\mathrm{E}$ coli 0157:H7 from sporadic cases of haemorrhagic colitis-United States. $M M W R$ 1982;31:580-5.

5 O'Brien AD, Lively TA, Chen ME, Rothman SW, Formal SB. Escherichia coli 0157:H7 strains associated with haemorrhagic colitis in the United States produce a Shigella dysenteriae 1 (Shiga) like cytotoxin. Lancet 1983;i:702.

6 Scotland SM, Smith HR, Rowe B. Two distinct toxins active on Vero cells from Escherichia coli 0157. Lancet 1985;ii:885-6.

7 Karmali MA, Petric M, Steele BT, Lim C. Sporadic cases of haemolytic uraemic syndrome associated with faecal cytotoxin and cytotoxin producing Escherichia coli in stools. Lancet 1983;i:619-20.

8 Karmali MA, Petric M, Lim C, Fleming PC, Arbus GS, Lior H. The association between idiopathic haemolytic uraemic syndrome and infection by verotoxin producing Escherichia coli. $J$ Infect Dis 1985;151:775-82.

9 Gransden WR, Damm MAS, Anderson JD, Carter JE, Lior H. Further evidence associating haemolytic uraemic syndrome with infection by verotoxin producing Escherichia coli 0157:H7. $J$ Infect Dis 1986;154:522-4.

10 Martin ML, Shipman LD, Wells JG, et al. Isolation of Escherichia coli 0157:H7 from dairy cattle associated with two cases of haemolytic uraemic syndrome. Lancet 1986;ii: 1043.

11 Spika JS, Parsons JE, Nordenberg D, Wells JG, Gunn RA, Blake PA. Haemolytic uraemic syndrome and diarrhoea associated with Escherichia coli 0157:H7 in a day care centre. $J$ Paediatr 1986;109:287-91.

12 Johnson WM, Lior H, Bezanson GS. Cytotoxic Escherichia coli 0157:H7 associated with haemorrhagic colitis in Canada. Lancet 1983;i:76.

13 Riley LW, Remis RS, Helgerson SD, et al. Haemorrhagic colitis associated with a rare Escherichia coli serotype. $N$ Engl J Med 1983;308:681-5.

14 Pai CH, Gordon R, Sims HV, Bryan LE. Sporadic cases of haemorrhagic colitis associated with Escherichia coli 0157:H7. Ann Intern Med 1984;101:738-42.

15 Ryan CA, Tauxe RV, Hosek GW, et al. Escherichia coli 0157:H7 diarrhoea in a nursing home: clinical, epidemiological and pathological findings. $J$ Infect $D$ is 1986;154:631-8.

16 Borczyk AA, Karmali MA, Lior H, Duncan LMC. Bovine reservoir for verotoxin-producing Escherichia coli 0157:H7. Lancet 1987; i:98.

17 Wells JG, Davis BR, Wachmuth IK, et al. Laboratory investigation of haemorrhagic colitis outbreaks associated with a rare Escherichia coli serotype. J Clin Microbiol 1983;18:512-20.

18 Farmer III JJ, Davis BR. H7 antiserum-sorbitol fermentation medium: a single tube screening medium for detecting Escherichia coli 0157:H7 associated with haemorrhagic colitis. J Clin Microbiol 1985;22:620-5.

19 March SB, Ratnam S. Sorbitol-MacConkey medium for detection of Escherichia coli $0157: \mathrm{H} 7$ associated with haemorrhagic colitis. J Clin Microbiol 1985;23:869-72.

20 Haldane DJM, Damm MAS, Anderson JD. Improved bio- 
chemical screening procedure for small laboratories for Vero (Shiga-like)-toxin-producing strains of Escherichia coli 0157:H7. J Clin Microbiol 1986;24:652-3.

21 Palmer SR. A community outbreak of haemorrhagic colitis due to Escherichia coli 0157:H7. Institute of Veterinary Medicine 1986;1:189.

22 Falkow S. Activity of lysine decarboxylase as an aid in the identification of Salmonella and Shigellae. Am J Clin Pathol 1958;29:598

23 Karmali MA, Petric M, Lim C, Cheung R, Arbus GS. Sensitive method for detecting low numbers of Verotoxin-producing Escherichia coli inmixed cultures by use of colony sweeps and polymyxin extraction of Verotoxin. $J$ Clin Microbiol 1985:22:614-9.
24 Smith HR, Rowe B, Gross RJ, et al. Haemorrhagic colitis and $\square$ vero-cytotoxin-producing Escherichia coli in England and $\underset{7}{\stackrel{2}{7}}$ Wales. Lancet 1987; i:1062-5.

25 'Krishnan C, Fitzgerald VA, Dakin SJ, Behme RJ. Laboratory investigation of outbreak of haemorrhagic colitis caused by Escherichia coli 0157:H7. J Clin Microbiol 1987;25:1043-7.

26 Doyle MP, Schoeni JL. Survival and growth characteristics of Escherichia coli associated with haemorrhagic colitis. Appl $\underline{\bar{\sigma}}$ Environ Microbiol 1984;48:855-6.

Requests for reprints to: $\mathrm{Mr} \mathrm{C}$ W Walker, Clinical $\stackrel{\mathbb{Q}}{\mathbb{Q}}$ Microbiology and Public Health Laboratory, Adden- ग) brooke's Hospital, Hills Road, Cambridge CB2 2QQ, England.
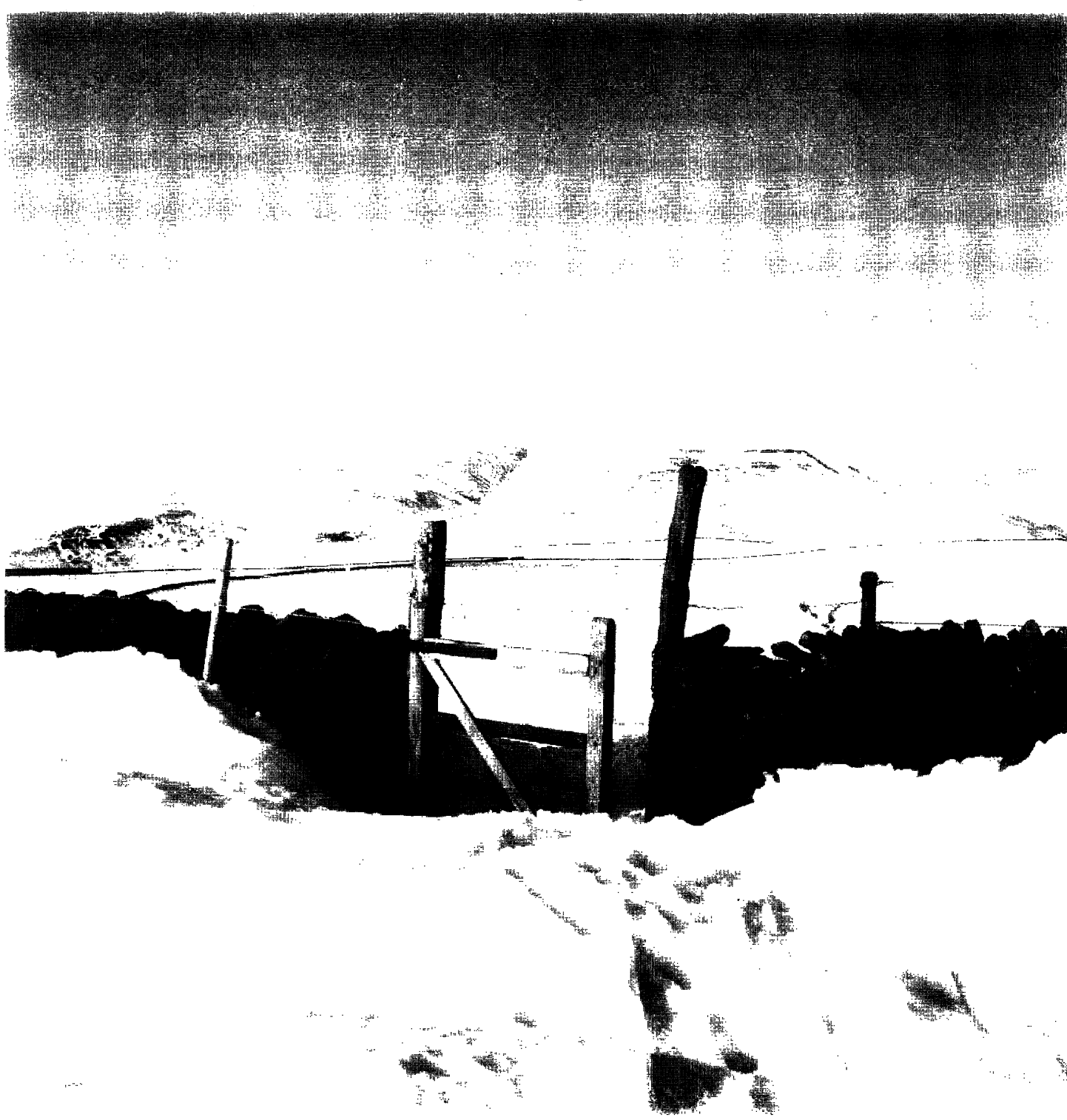

Kinder from the North, W R Timperley. 